\title{
PENERAPAN PEMBANGKIT TENAGA LISTRIK TENAGA BAYU SKALA KECIL SEBAGAI MEDIA PEMBELAJARAN DI SMK NEGERI 1 WONOSARI KABUPATEN MALANG
}

\author{
Awan Uji Krismanto ${ }^{1}$, Abraham Lomi ${ }^{2}$, Abdul Hamid ${ }^{3}$ \\ 1,2,3 Institut Teknologi Nasional Malang \\ e-mail : Awan_uji_krismanto@lecturer.itn.ac.id
}

\begin{abstract}
Abstrak - Desa Sumberdem terletak diwilayah Kecamatan Wonosari Kabupaten Malang dengan luas 426.310 Ha. Desa ini terbagi menjadi empat Dusun yaitu Dusun Sumberingin, Rekesan, Duren Gede dan Sumber Gelang. Terletak di lereng Gunung Kawi, Desa Sumberdem memiliki penduduk sejumlah 4686 jiwa yang terdiri dari 2328 laki laki dan 2358 perempuan. Penduduk tersebut tergabung dalam $1296 \mathrm{KK}$ yang terbagi menjadi lima kategori yaitu Pra sejahtera 125 KK, sejahtera I sebanyak 421 KK, sejahtera II sebanyak $413 \mathrm{KK}$, sejahtera III sebanyak $254 \mathrm{KK}$, sejahtera III plus sebanyak 83 KK. Dari segi tingkat pendidikan, penduduk Desa Sumberdem memiliki tingkat pendidikan yang beragam. Tercatat 145 orang buta huruf, 161 tidak lulus SD, 2912 orang tamat SD, 543 orang tamat SLTP, 381 orang SLTA, 31 berpendidikan S1 dan S2 sebanyak 1 orang. Di Desa Sumberdem terdapat sebuah SMKN 1 Wonosari yang memiliki jurusan salah satunya energi terbarukan (renewable energy). Dari sektor pendidikan ini dapat kami lakukan pengabdian dengan memberikan bantuan hibah peralatan pembangkit listrik tenaga bayu skala kecil sebagai media pembelajaran siswa SMKN 1 Wonosari untuk memberikan pengetahuan dan wawasan teknologi pembangkit listrik tenaga bayu.
\end{abstract}

Kata Kunci: Energi terbarukan, pembangkit listrik, kincir angin sumbu vertikal, skala kecil, media pembelajaran.

Abstract - Sumberdem Village is located in Wonosari District, Malang Regency with an area of 426,310 Ha. The village was divided into four hamlets, namely Sumberingin, Rekesan, Duren Gede and Sumber Gelang hamlets. Located on the slopes of Mount Kawi, Sumberdem Village has a population of 4686 people consisting of 2328 men and 2358 women. These residents are members of 1296 families which are divided into five categories, namely Pre-prosperous 125 families, Prosperous I as many as 421 families, Prosperity II as many as 413 families, Prosperity III as many as 254 families, Prosperity III plus as many as 83 families. In terms of education level, the residents of Sumberdem Village have various levels of education. There were 145 illiterate people, 161 did not graduate from elementary school, 2912 people graduated from elementary school, 543 people graduated from junior high school, 381 people graduated from high school, 31 had bachelor's and master's degrees a1 person. SMKN 1 Wonosari where located in Sumberdem Village which has a major one of them is renewable energy. From this education sector, we can do service by providing grant assistance for small-scale wind power generation equipment as a learning medium for students of SMKN 1 Wonosari to provide knowledge and insight into wind power plant technology.

Keywords : Renewable energy, power generation, vertical axis windmills, small scale, learning media. 


\section{PENDAHULUAN}

Desa Sumberdem terletak pada posisi 661000-663250 Lintang selatan dan 9107900- 9111900 Bujur Timur dengan ketinggian 660-790 m diatas permukaan air laut. Desa Sumberdem terletak di wilayah Kecamatan Wonosari, Kabupaten Malang yang dibatasi oleh Desa Wonosari di sebelah utara, Desa Ampelgading, Kecamatan Selorejo Kabupaten Blitar di sebelah barat, Desa Jambuwer, Kecamatan Kromengan, Kabupaten Malang di sebelah selatan, serta Desa Sumbertempur Kecamatan Wonosari, Kabupaten malang di sebelah timur. Jarak tempuh Desa Sumberdem ke ibu kota kecamatan adalah $5 \mathrm{~km}$, jarak tempuh ke ibu kota kabupaten Malang sejauh 37 $\mathrm{km}$ sedangkan jarak tempuh ke ibu kota Malang sekitar 43,9 km. Luas Desa Sumberdem 426,310 Ha yang diperuntukkan untuk fasilitas umum perkantoran, pertokoan, pasar dan jalan seluas $8.870 \mathrm{Ha}$, sekolah $0.570 \mathrm{Ha}$, olahraga 0.6 Ha dan tempat pemakaman umum $1 \mathrm{Ha}$. Luas lahan pemukiman $89.972 \mathrm{Ha}$, pertanian 30.440 $\mathrm{Ha}$, tegalan dan perkebunan $294.133 \mathrm{Ha}$, peternakan 0,725 Ha. Lahan terbesar digunakan untuk pertanian dan perkebunan kopi.

Hasil bumi di Desa Sumberdem terdapat tanaman obat - obatan yang salah satunya daun afrika sedangkan hasil bumi lainnya meliputi kopi, cengkeh, kelapa, jagung, kakao, padi, singkong dan ubi jalar, bambu. Selain itu terdapat potensi hasil buah-buahan berupa durian, jambu, nangka, sirsak dan jeruk punten. Desa Sumberdem yang terletak di lereng Gunung Kawi, terdiri atas empat dusun yaitu dusun Sumberingin yang mempunyai mata air di bawah pohon beringin dengan debit air kurang lebih 25 liter/detik, dusun Rekesan, dusun Duren Gede sebagai penghasil durian, dan dusun Sumbergelang yang memiliki pusat industri kecil mebel. Selain sumber hasil pertanian, potensi energi baru terbarukan (EBT) di desa Sumberdem cukup menjanjikan. Energi air skala kecil (mikrohidro) menjadi salah satu potensi yang ada. Terdapat sungai-sungai kecil dengan aliran air cukup deras (debit air sekitar 20 liter/detik). Terletak di perbukitan, energi angin dengan kecepatan rata-rata $5-7 \mathrm{~m} / \mathrm{s}$ dan energi surya juga merupakan potensi energi yang dapat dikembangkan.

Perkembangan energi angin di Indonesia untuk saat ini masih tergolong rendah namun punya potensi yang sangat besar. Salah satu penyebabnya adalah karena kecepatan angin rata- rata di wilayah Indonesia tergolong kecepatan angin rendah, yaitu berkisar antara $3 \mathrm{~m} / \mathrm{s}$ hingga $5 \mathrm{~m} / \mathrm{s}$ sehingga sulit untuk menghasilkan energi listrik dalam skala besar. Meskipun demikian, potensi angin di Indonesia tersedia hampir sepanjang tahun, sehingga memungkinkan untuk dikembangkan sistem pembangkit listrik skala kecil. Salah satu upaya yang dapat dilakukan yaitu dengan melakukan kajian teknis terhadap mesin konversi energi yang dapat digunakan untuk memanfaatkan sumber energi terbarukan secara optimal dalam menghasilkan energi listrik.

Berdasarkan survei lapangan di SMKN 1 Wonosari jurusan Energi Terbarukan, terdapat beberapa permasalahan belum adanya media pembelajaran yang memadai untuk praktek menggunakan peralatan yang berhubungan dengan pembangkit listrik tenaga bayu. Pembangkit listrik tenaga bayu skala kecil terdiri dari beberapa komponen utama yaitu yang pertama adalah kincir angin sumbu vertikal model Savonius sebagai turbin untuk menggerakkan generator, kemudian yang ke dua adalah generator magnet permanen fluks radial putaran rendah sebagai pembangkit listrik, selanjutnya yang ke tiga adalah modul kontrol sebagai alat untuk mengontrol tegangan yang fluktuatif sesuai dengan putaran tubin angin dan penyearah sebagai penyearah tegangan AC 
menjadi tegangan DC, yang ke empat adalah baterai/accu sebagai penyimpan energi listrik.

Teknologi kincir angin terus dikembangkan agar dapat dimanfaatkan dalam kondisi kecepatan angin yang berubah-ubah. Untuk itu, dalam pengabdian kepada masyarakat iniakan dihibahkan peralatan lengkap pembangkit listrik tenaga bayu skala kecil menggunakan kincir angin sumbu vertikal dan menggunakan generator magnet permanen sebagai media pembelajaran siswa SMKN 1 Wonosari jurusan Renewable Energy (Energi Terbarukan) agar mempunyai wawasan pengetahuan dan teknologi bagaimana memanfaatkan potensi angin yang ada di Desa Sumberdem Kecamatan Wonosari Kabupaten Malang.

\section{METODE}

\section{A. Perancangan Kincir Angin Sumbu Vertikal}

Perancangan kincir angin sumbu vertikal, dalam proses perancangan kincir angin sumbu vertikal, untuk menghasilkan daya yang cukup untuk memenuhi kebutuhan listrik skala kecil sebaiknya didasarkan dari beberapa faktor-faktor yang mendukung efektifitas daya yang dihasilkan turbin tersebut. Banyak model atau jenis kincir angin sumbu vertikal, dari beberapa faktor yang harus dipertimbangkan dalam penelitian ini dipilih jenis Lenz2 dengan tiga buah blade yang perancangannya ditunjukkan pada Gambar 1.

Desain blade vertikal Lenz2 merupakan pilihan yang sangat tepat, karena pada kerangkanya terdapat lengkungan yang dapat menangkap angin lebih banyak dari segalah arah sampai $360^{\circ}$. Kerangka blade tersebut terbuat dari bahan yang ringan sehingga jika terkena sedikit angin akan berputar. Pada ketiga blade tersebut terdapat poros tengah yang digunakan untuk menggabungkannya. Poros tengah tersebut tersambung terhubung pada bearing dan juga generator.
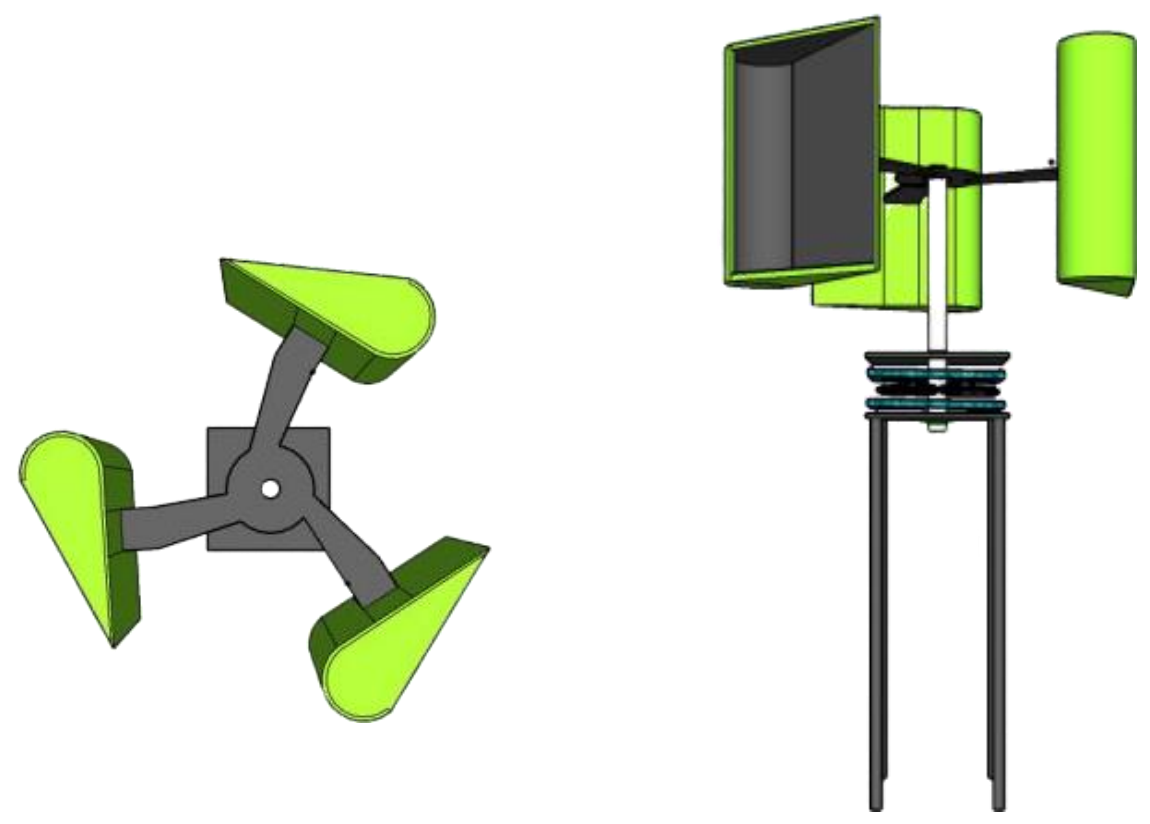

Gambar 1. Desain kincir angin dengan tiga buah blade sumbu vertikal jenis Lenz2 
B. Pembuatan Kincir Angin Sumbu Vertikal

Dalam proses pembuatan kincir angin sumbu vertikal jenis Lenz2 dipilih bahan material untuk rangka blade dari besi pipa kotak dan untuk blade dari bahan plat aluminium yang hasilnya seperti ditunjukkan pada Gambar 2.
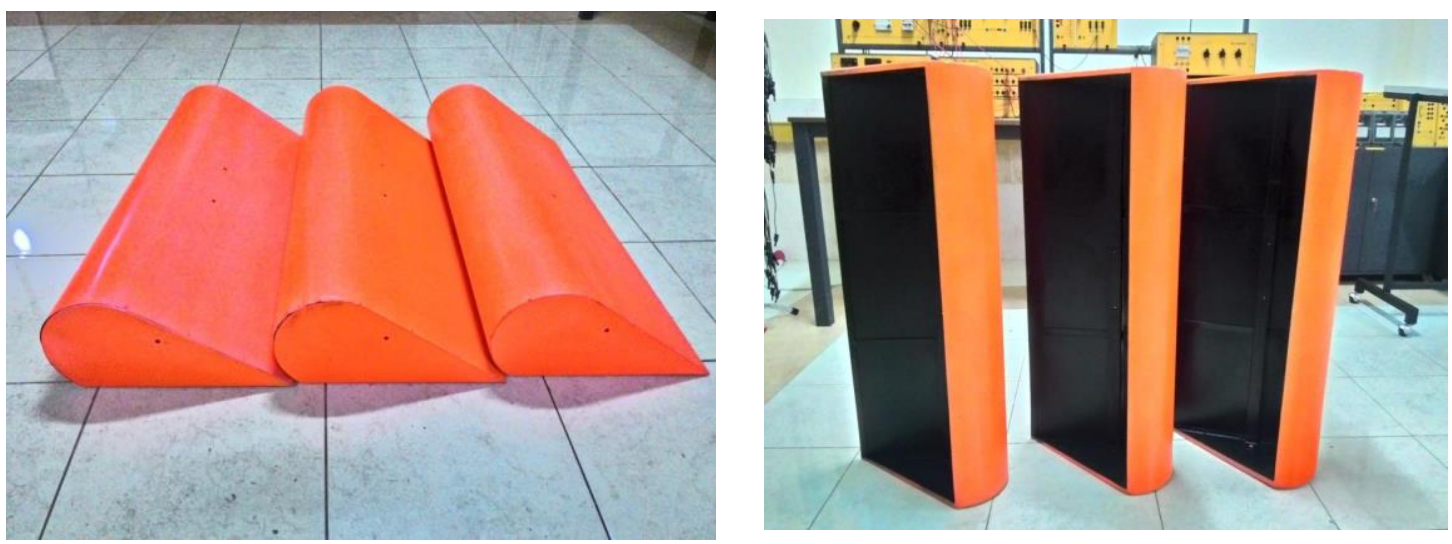

Gambar 2. Hasil pembuatan blade kincir angin jenis Lenz2

Rumah generator terpasang pada tower yang menopang turbin angin tersebut, tower memiliki ketinggian empat meter yang dipotong menjadi dua bagian, dimana satu bagian memiliki panjang dua meter. Tower tersebut bisa dibongkar pasang, sehingga memudahkan untuk di bawa keman saja tanpa harus memerlukan ruang yang banyak untuk mengangkutnya. Tower di desain dengan lebar pada bagian bawah adalah $60 \mathrm{~cm}$ dan bagian atas $30 \mathrm{~cm}$. Tower dan bantalan rumah generator didesain secara portabel ditunjukkan pada Gambar 3 .
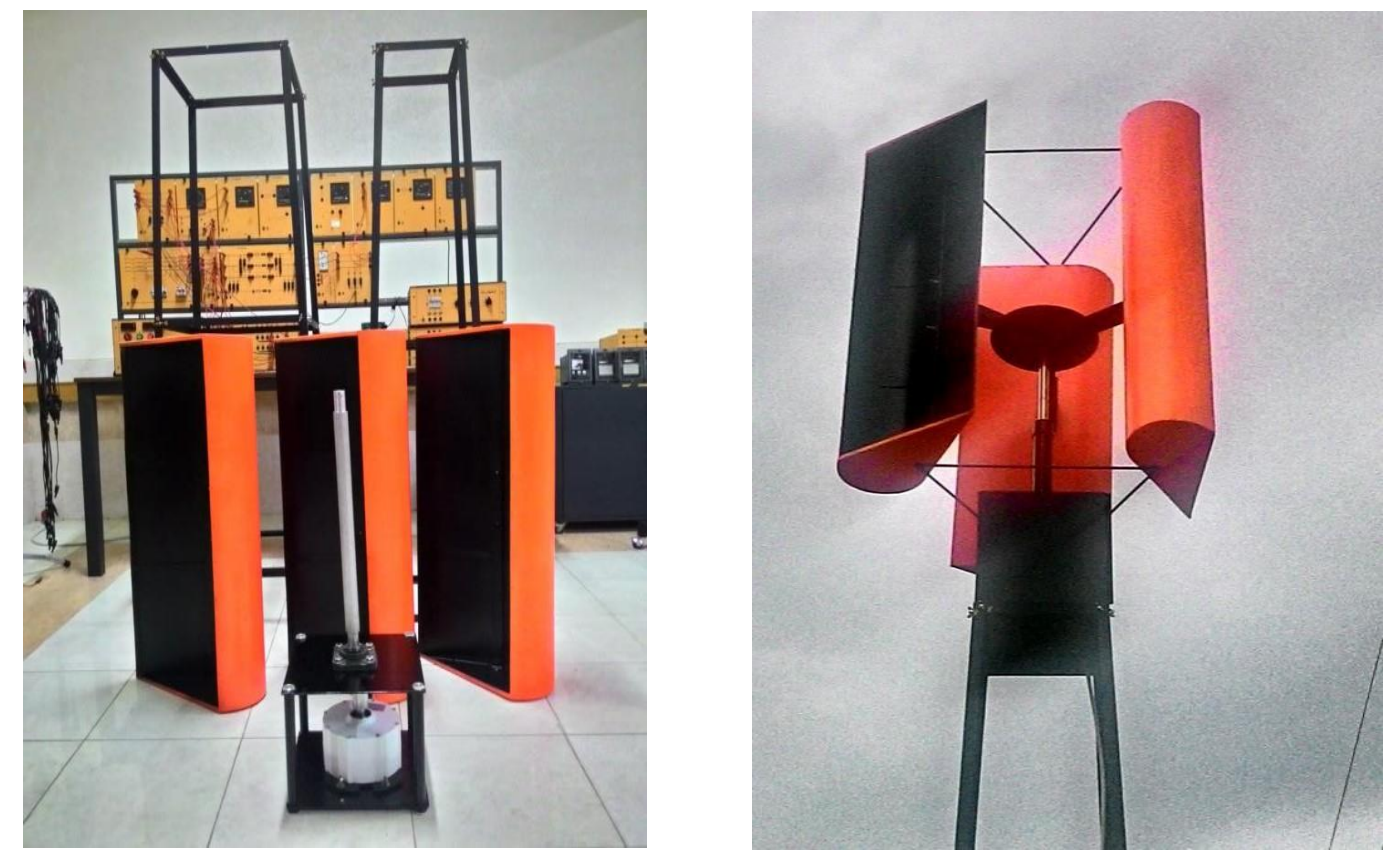

Gambar 3. Konstruksi bagian-bagian utama kincir angin sumbu vertikal yang terdiri dari rumah generator, blade dan tiang penyangga 


\section{Perancangan Generator Magnet Permanen}

Dalam merancang generator magnet permanen terlebih dahulu dilakukan pembuatan desain dudukan rotor, desain stator, serta desain poros. Desain proses berguna untuk mengintegrasikan semua proses yang terjadi dalam aplikasi yang di buat. Desain data berguna untuk mengetahui apa saja yang dibutuhkan dalam proses yang akan dikerjakan sedangkan perancangan alat dengan kapasitas yang kita inginkan di butuhkan beberapa perhitungan seperti perhitungan dimensi magnet,dan data kerapan fluks magnet tersebut sehingga kita dapat menghitung fluks magnet, serta perhitungan daya yang dihasilkan generator sehingga dapat mempermudah dalam pengerjaan pembuatan generator sesuai daya yang diinginkan.

Beberapa parameter yang dapat menentukan kapasitas daya generator yang diinginkan seperti, kekuatan fluks magnet, jumlah kumparan dan belitannya,jumlah magnet serta ukuran diameter kawat.

Generator yang akan dibuat menggunakan satu buah rotor dan satu buah stator yang disebut cakram tunggal. Pada bagian rotor terdiri dari tiga bagian utama yaitu cetakan magnet rotor,magnet permanen dan dudukan magnet yang terbuat dari akrilick (acrylic). Magnet permanen pada rotor ditanam pada akrilick sesuai dengan ketebalan magnet.Susunan magnet yang digunakan pada pada generator ini adalah N-S, dimana susunan magnet permanen berlawanan dengan arah kiri dan kanannya.Hal ini dikarenakan penyebaran fluks yang dihasilkan akan lebih rapat sehingga kumparan stator dapat menangkap fluks lebih efektif. Magnet permanen yang digunakan adalah Neodymium Br 1,17 Tesla.

Stator yang direncanakan memilliki enam belas kumparan hal ini mengikuti jumlah magnet yang digunakan, hal ini mempertimbangkan sapuan fluks magnet akan lebih efektif ditangkap oleh kumparan stator. Kumparan-kumparan tersebut semuanya disusun seri dikarenakan generator magnet permanen yang akan dibuat hanya dengan keluaran satu fasa saja, sedangkan jenis kawat tembaga email yang direncanakan dipakai berjenis $\mathrm{F}$ class dengan diameter kawat tembaga email 0,8 $\mathrm{mm}$ dengan lebar dari perkumparan stator mempertimbangkan posisi jarak antar magnet rotor hal ini dikarenakan agar kumparan stator dapat menangkap fluks magnet yang dihasilkan rotor dengan baik.

Data spesifikasi desain generator ini didapat dari sisi desain rotor dan dari sisi desain generator, yang nantinya sangat diperlukan untuk mengetahui daya keluaran generator melalui proses perhitungan sesuai dengan rumus-rumus didasar teori.datadata keseluruhan desain generator yang akan dibuat dapat dilihat pada Tabel 1.

Tabel 1. Data spesifikasi desain generator magnet permanen cakram tunggal

\begin{tabular}{|c|l|c|}
\hline Rotor & \multicolumn{1}{|c|}{ Keterangan } & Ukuran \\
\hline $\mathrm{P}$ & Panjang magnet & $0,05 \mathrm{~m}$ \\
\hline $\mathrm{L}$ & Lebar magnet & $0,015 \mathrm{~m}$ \\
\hline $\mathrm{T}$ & Tebal magnet & $0,006 \mathrm{~m}$ \\
\hline $\mathrm{Tf}$ & Jarak antar magnet & $0,04 \mathrm{~m}$ \\
\hline ri & Radius dalam magnet & $0,09 \mathrm{~m}$ \\
\hline ro & Radius luar magnet & $0,14 \mathrm{~m}$ \\
\hline $\mathrm{Nm}$ & Jumlah magnet & 16 \\
\hline
\end{tabular}




\begin{tabular}{|c|l|c|}
\hline Ndfeb & Jenis magnet & \\
\hline $\mathrm{Br}$ & Kerapan fluks magnet & $1,17 \mathrm{~T}$ \\
\hline & Tebal rotor & $0,009 \mathrm{~m}$ \\
\hline Stator & keterangan & ukuran \\
\hline $\mathrm{N}$ & Jumlah lilitan & 100 \\
\hline $\mathrm{Ns}$ & Jumlah kumparan & 16 \\
\hline $\mathrm{Nph}$ & Jumlah fasa & 1 \\
\hline & Diameter kawat & $0,8 \mathrm{~mm}$ \\
\hline F class & Jenis kawat & \\
\hline & Tebal stator & $1,3 \mathrm{~cm}$ \\
\hline$\delta$ & Celah udara & $3 \mathrm{~mm}$ \\
\hline
\end{tabular}

\section{HASIL KARYA UTAMA DAN PEMBAHASAN}

Teknologi kincir angin yang dikembangkan diharapkan dimanfaatkan dalam kondisi kecepatan angin yang berubah-ubah. Untuk itu, dalam pengabdian kepada masyarakat ini akan dihibahkan peralatan lengkap pembangkit listrik tenaga bayu skala kecil menggunakan kincir angin sumbu vertikal jenis Lenz dan menggunakan generator magnet permanen sebagai media pembelajaran siswa SMKN 1 Wonosari jurusan Renewable Energy (Energi Terbarukan) agar mempunyai wawasan pengetahuan dan teknologi bagaimana memanfaatkan potensi angin yang ada di Desa Sumberdem Kecamatan Wonosari Kabupaten Malang. Gambaran IPTEK pembangkit listrik tenaga bayu sumbu vertical yang digunakan sebagai media pembelajaran di SMKN 1 Wonosari ditunjukkan pada gambar 6 .

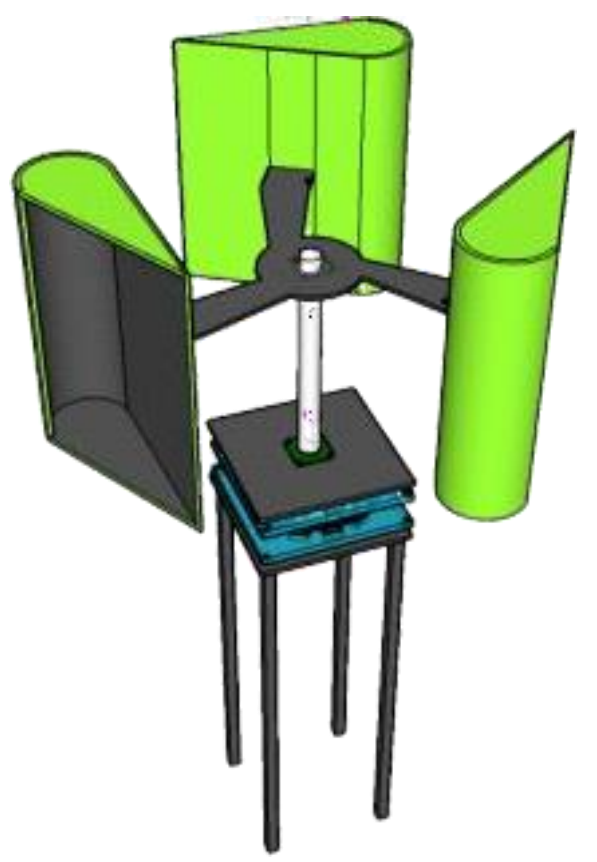

Gambar 6. Gambaran IPTEK pembangkit listrik tenaga bayu sumbu vertikal skala kecil

Proses pelaksanaan kegiatan pengabdian masyarakat di SMKN 1 Wonosari Malang dimulai dari tahap survey lokasi, koordinasi dan diskusi dengan pihak mitra, persiapan desain dan pembuatan alat, uji coba dan pemasangan alat di lokasi. Tahapan 
kegiatan tersebut dilaksanakan dalam jangka waktu 8 bulan dan telah diselesaikan dengan baik. Pada saat ini, kincir angin yang telah dipasang telah dapat digunakan an untuk media pembelajaran para siswa SMKN 1 Wonosari. Dengan adanya alat peraga tersebut, pemahaman siswa tentang implementasi pembangkit listrik tenaga bayu dapat lebih meningkat dan siswa memiliki pengetahuan tentang desain, perancangan, pembuatan, pengujian serta pengoperasian pembangkit listrik tenaga bayu skala kecil.

Dokumentasi kegiatan pengabdian masyarakat di SMKN 1 Wonosari mulai dari proses survei lapangan, diskusi dengan mitra ditunjukkan pada gambar 7. Proses pemasangan alat dilakukan dengan kerja sama antara teknisi dari ITN Malang dan SMKN 1 Wonosari. Proses pemasangan pembangkit listrik tenaga bayu skala kecil ditunjukkan pada gambar 8.
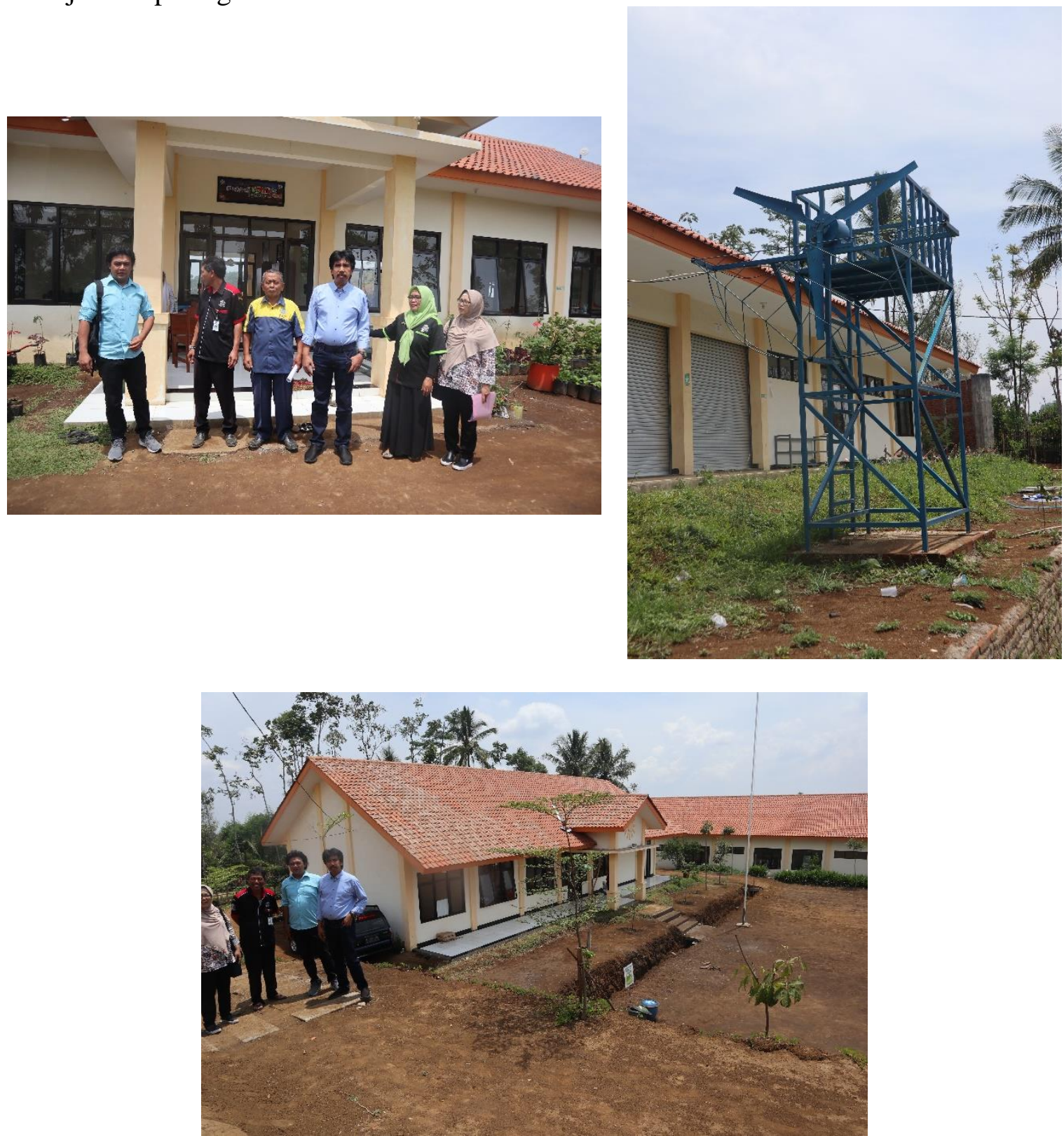

Gambar 7. Survei Lokasi SMKN 1 Wonosari 


\section{JASTEN}
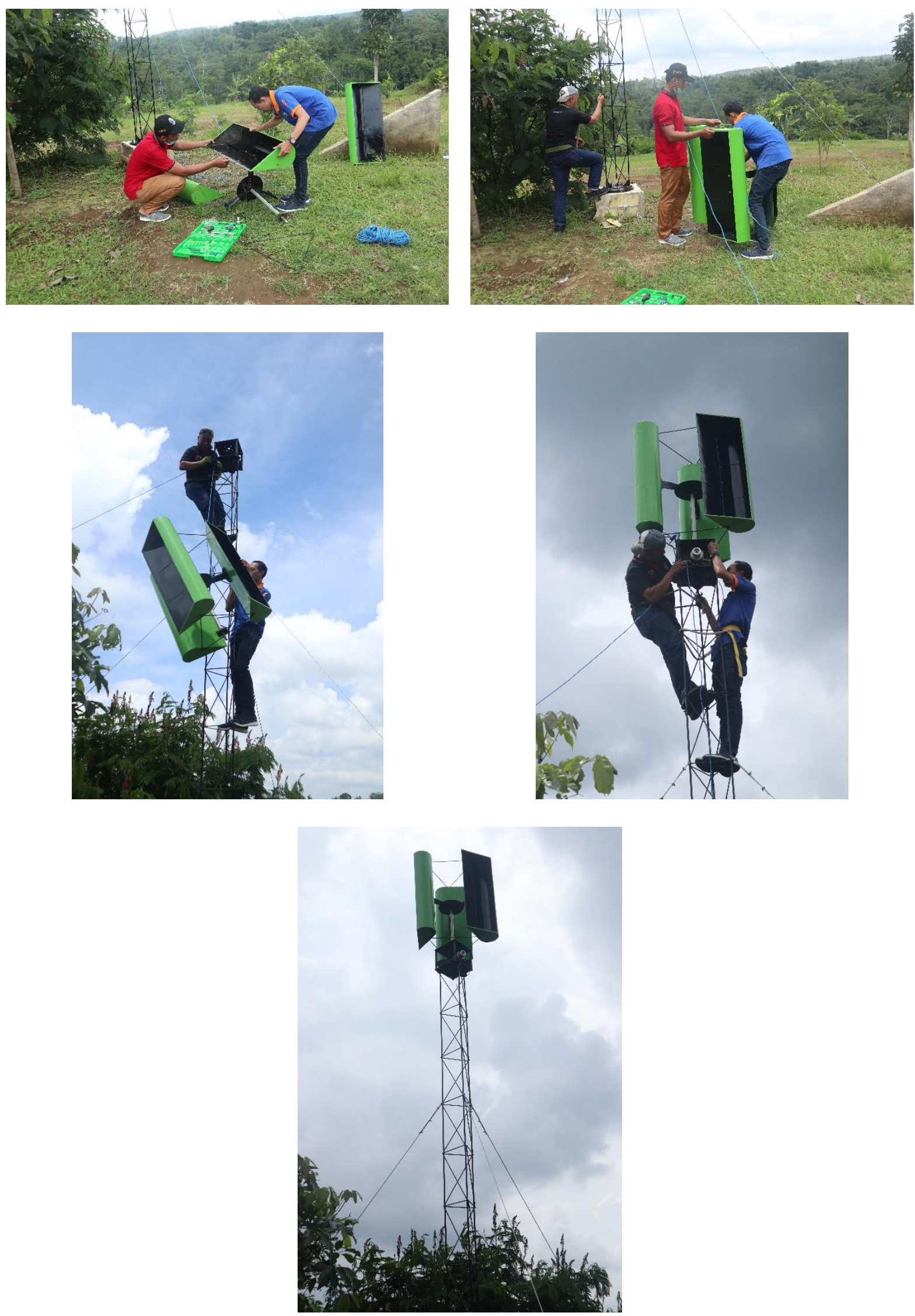

Gambar 8. Proses Pemasangan Pembangkit Listrik Tenaga Bayu Skala Kecil di SMKN 1 Wonosari 


\section{KESIMPULAN}

Dari pekerjaan pengabdian masyarakat yang telah dilakukan di SMKN 1 Wonosari, didapatkan bahwa desain dan proses pembuatan alat disimpulkan sudah sesuai dengan yang diinginkan oleh mitra dan proses pembuatan PLTB skala kecil sudah dilakukan. Pelatihan pengoperasian PLTB sudah dilakukan dan digunakan untuk meningkatkan kualitas pembelajaran di SMKN 1 Wonosari.

\section{UCAPAN TERIMA KASIH}

Terima kasih kepada ITN Malang untuk pendanaan kegiatan pengabdian masyarakat di SMKN 1 Wonosari

\section{DAFTAR PUSTAKA}

Culp, Archie W., 1991. Prinsip-Prinsip Konversi Energi. Jakarta: Erlangga. Terjemahan: Principles of Energy Conversion. 1979. McGraw-Hill, Ltd

Daryanto, Y., 2007. Kajian Potensi Angin Untuk Pembangkit Listrik Tenaga Bayu. Balai PPTAGG - UPT-LAGG

Dutta, Animesh. 2006. Basics of Wind Technology. Asian Institute of Technology Thailand. 6 Juli 2006

Guntoro, W., 2008. Studi Pengaruh Panjang dan Jumlah Baling-Baling Terhadap Efisiensi Daya Listrik Pada Pembangkit Listrik Tenaga Angin. Bandung:ITB

Kamal, Faizul M., 2008. Aerodynamics Characteristics of A Stationary Five Bladed Vertical Axis Vane Wind Turbine. Journal of MechanicalEngineering, Vol. ME39, No. 2, pp. 95-99.

Khan, N.I., Iqbal, M.T., Hinchey, Michael, dan Masek, Vlastimil. 2009.Performance of Savonius Rotor As A Water Current Turbine. Journal ofOcean Technology. Vol. 4, No. 2, pp. 71-83.

Mittal, Neeraj. 2001. Investigation of Performance Characteristics of a NovelVAWT. Thesis. UK: Departement of Mechanical Engineering University ofStrathclyde

Nakajima, M., Lio, S., dan Ikeda, T., 2008. Performance of Double-step SavoniusRotor for Environmentally Friendly Hidroulic Turbine. Journal of FluidScience And Technology. Volume 3 No. 3, pp 410-419

Nakajima, M., Lio, S., dan Ikeda, T., 2008. Performance of Savonius Rotor forEnvironmentally Friendly Hidroulic Turbine. Journal of Fluid ScienceAnd Technology. Volume 3 No. 3, pp 420-429

Rosidin, Nanang. 2007. Perancangan, Pembuatan, dan Pengujian PrototipeSKEA Menggunakan Rotor Savonius dan Windside Untuk PeneranganJalan Tol. Bandung: ITB

Soelaiman, F., Tandian, Nathanael P., dan Rosidin, N., 2006. Perancangan,Pembuatan dan Pengujian Prototipe SKEA Menggunakan Rotor Savoniusdan Windside untuk Penerangan Jalan Tol; Bandung. ITB. 